\title{
Annual Breast Cancer Screening Beginning at Age 40: Why Should Portugal Choose Wisely?
}

\author{
Rastreio Anual de Cancro da Mama a Partir dos 40 Anos \\ de Idade: Porque é que Portugal o Deve Implementar?
}

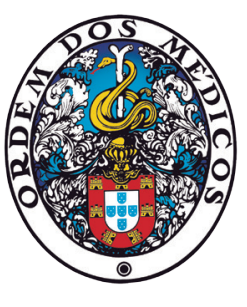

Carlos Francisco SILVA ${ }^{1}$, Elisa MELO ABREU², José Carlos MARQUES ${ }^{3}$, Kara-Lee POOL ${ }^{4}$ Acta Med Port 2021 Nov;34(11):717-720 - https://doi.org/10.20344/amp.16601

Keywords: Breast Neoplasms/diagnostic imaging; Clinical Decision-Making; Guideline Adherence; Portugal; Quality Assurance Palavras-chave: Adesão a Directrizes; Garantia da Qualidade dos Cuidados de Saúde; Neoplasias da Mama/diagnóstico por imagem; Portugal; Tomada de Decisão Clínica

The age at which women of average risk should initiate breast cancer screening and the optimal screening interval (annual or biennial) is currently prone to scientific controversy. The United States Preventive Services Task Force (USPSTF), released in 2016 the following recommendations ${ }^{1}$ that ultimately led to this divisive discussion:

1. women between 40-49 years old who place a higher value on the potential benefit than the potential harms may choose to begin biennial screening. This decision should be individualized (Level $\mathrm{C}$ recommendation);

2. biennial screening mammography for women aged 50-74 years old (Level B recommendation).

The USPSTF recommendations tend to have high acceptance among North American primary care clinicians and are thus usually followed by Portuguese family physicians as well. The American College of Radiology (ACR), with its breast imaging experts, was the first organization to criticize the USPSTF recommendation, not only by publishing scientific papers, comments and different guidelines, but also by dealing with the problem of misinformation among patients: under the umbrella term "Mammography Saves Lives", a coalition of many medical associations, free educational content was produced and released through several media platforms (link providing access to the free educational videos on YouTube, addressing common breast cancer screening misconceptions, with the ultimate goal of helping women and their healthcare providers making better-informed shared decisions: goo.gl/DEf5wj).

The Portuguese College of Radiology is aligned with the $A C R$, and has just recently issued a similar recommendation in the Choosing Wisely Portugal campaign (bit.ly/cwp-

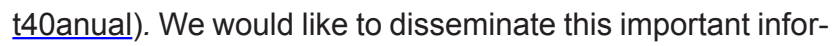
mation, and we summarize the most important arguments supporting our recommendation below.

\section{QUESTION 1}

When to begin the screening: at $\mathbf{4 0}$ years old or later?

The USPSTF recommendation concerning starting screening at age 40 was based on balancing the number of deaths avoided with the risk of harm, with 'harm' including the issues of overdiagnosis and the high rate of recalls from screening mammography. So far, in Portugal, the recall is not seen as a major issue, and no big discussion arose, neither on social or medical grounds, as in North America.

The meta-analyses supported by the Cancer Intervention and Surveillance Modeling Network (CISNET) population models and the Breast Cancer Surveillance Consortium were pivotal in the USPSTF decision. ${ }^{1}$ The well-known Canadian National Breast Screening Study (CNBSS-1) was also included among them, whose results showed no benefit for women aged from 40 to 59 . As somewhat expected, this study had considerable flaws: poor quality mammograms and an unblinded allocation leading to a major imbalance (a non-blinded physical examination, resulting in significantly more women with advanced-stage cancers being allocated to the screening group). ${ }^{2}$

Regarding the issue of overdiagnosis, a landmark paper is often used to support the claims of high levels of overdiagnosis in breast cancer screening as high as 31\%. ${ }^{3}$ But once again, this study was very criticized by the radiological expert community, namely for failing to account or adjust for lead time bias and grossly underestimating the background cancer incidence rate increase. ${ }^{4}$ As lead time modelling for overdiagnosis seems to gain preference within the expert community, it is now well known that most studies with adjustment for lead time and risk status found overdiagnosis rates mainly within the range of $0 \%$ to $5 \%$, while studies with inadequate adjustment generally found (inaccurate) rates of $20 \%$ to nearly $60 \%$. $^{5}$

Some have stated that the natural course of some screen-detected invasive breast cancers is possibly

\footnotetext{
1. Serviço de Imagiologia. Centro Hospitalar de Setúbal. Setúbal. Portugal.

2. Serviço de Radiologia. Centro Hospitalar Universitário do Porto. Porto. Portugal.

3. Serviço de Radiologia. Instituto Português de Oncologia de Lisboa Francisco Gentil. Lisboa. Portugal.

4. RAD-AID International. Chevy Chase. United States of America.

$\triangle$ Autor correspondente: Carlos Francisco Silva. carlos.f.silva@chs.min-saude.pt

Recebido: 24 de maio de 2021 - Aceite: 19 de julho de 2021 - Online issue published: 02 de novembro de 2021

Copyright $\odot$ Ordem dos Médicos 2021
} 
spontaneous regression ${ }^{6}$. However, there does not seem to be a single credible report in the scientific peer-reviewed literature of an invasive breast cancer disappearing on its own without therapy. ${ }^{7}$ For breast radiologists, the arguments against breast cancer screening seem to have gone from ridiculous ("Mammography squeezes cancer into the blood causing early death") 8,9 to the outrageous ("Breast cancer would melt away if left untreated"). ${ }^{6}$

Some even claim that the reduction in breast cancer A

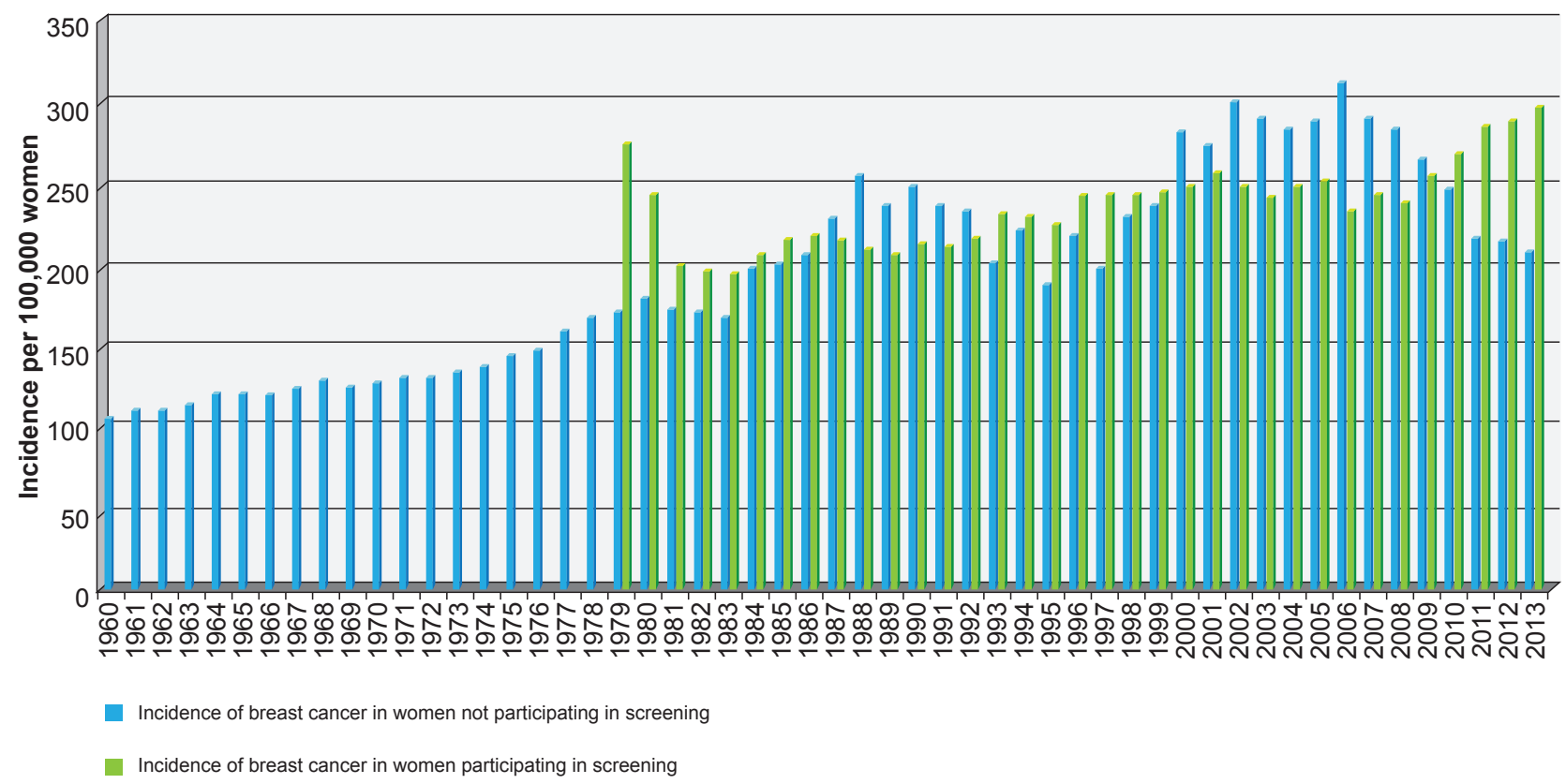

B

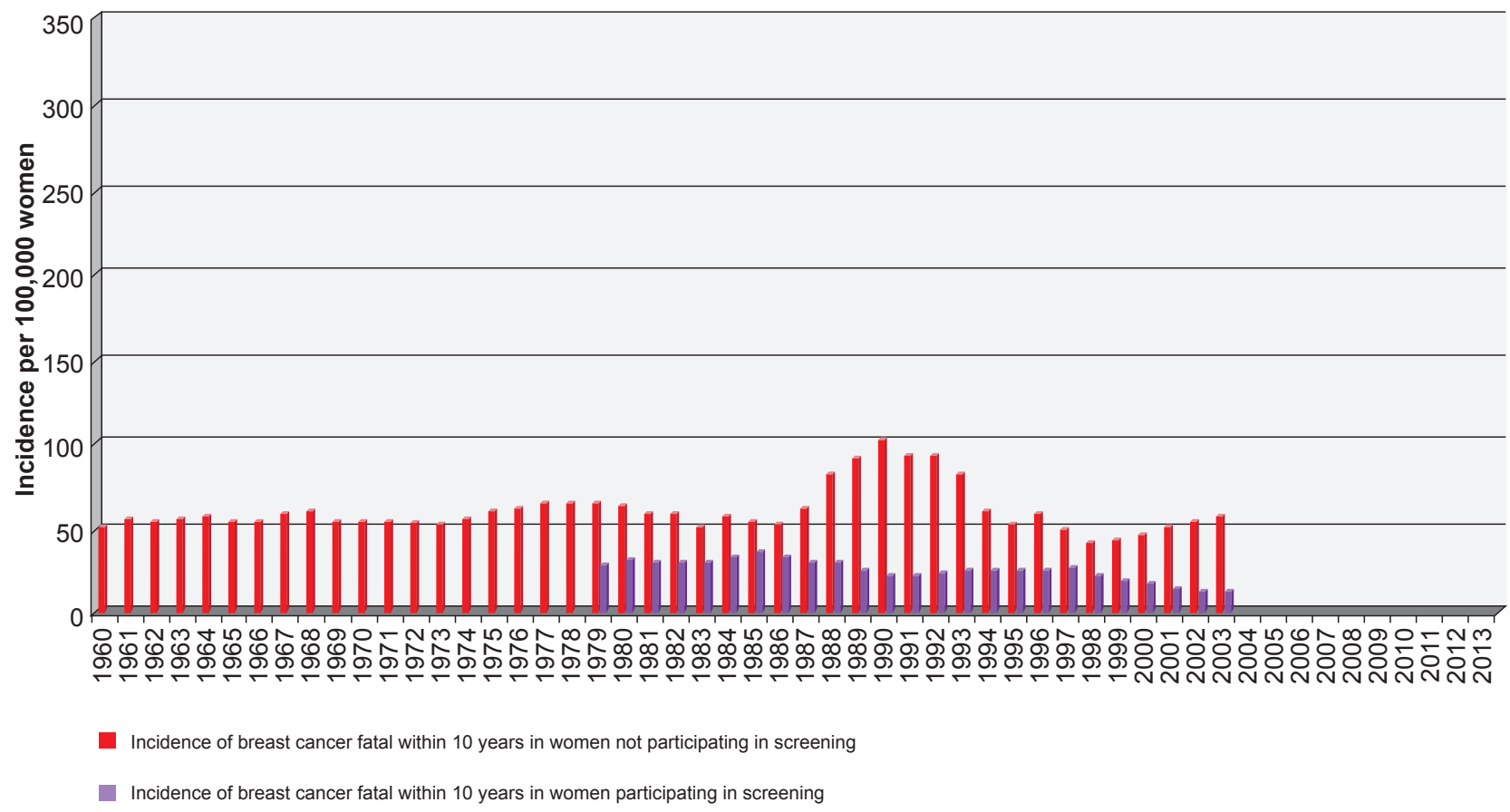

Figure 1 - The incidence of (A) breast cancer and of (B) breast cancer leading to death within 10 years among women who did and did not participate in mammography screening is illustrated. All values indicate 5 -year moving averages for women aged between 40 and 69 years old (data from statistics of Dalarna County, Sweden, from 1958 to 2015).

Graphic remade in vectorial format by Acta Médica Portuguesa, reproduced with permission from Tabár $\mathrm{L}$, et al. The incidence of fatal breast cancer measures the increased effectiveness of therapy in women participating in mammography screening. Cancer. 2019;125:515-23.11 


\section{QUESTION 2}

\section{Annual or biennial screening?}

The USPSTF decision to pursue a biennial interval was again, mainly based on the CISNET data, showing a minor benefit when comparing annual to biennial screening. CISNET data suggested that biennial screening maintains $81 \%$ of mortality benefit, with almost half the rate of false positives. ${ }^{1,12}$

However, the USPSTF expert panel seemed once again to undermine the fact that this $19 \%$ decrease in benefits from annual to biennial screening predominantly affects women of younger age. One must remember that breast cancer in younger patients tends to be more aggressive, fast-growing and to have less favorable outcomes. ${ }^{13}$ The annual interval recommended by the ACR is based upon an estimated sojourn time (the asymptomatic period during which a breast cancer can be detectable by mammography) of 18 months in most breast cancers. Longer intervals will only increase the risk of lesions presenting with worse prognosis during screening intervals (significantly higher incidence of late-stage cancer). Larger and more aggressive tumors increase mortality, costs and morbidity (aggressive chemotherapy, higher recovery time, higher mastectomy rates). ${ }^{14}$

There is also some concern among the lay public about the risk of radiation-induced breast cancer in mammography. But recently, in 2015, the well renowned International Agency for Research on Cancer (IARC) stated that the risk of radiation-induced breast cancer due to screening mammography is at least 100 times lower than the probability of avoiding a breast cancer death in the same screening cohort, and for a wide range of ages. ${ }^{15}$ Importantly, most radiation-induced breast cancers could be cured, and therefore radiation risk should not be a deterrent from screening. ${ }^{16}$

\section{QUESTION 3}

\section{When to stop screening?}

The USPSTF has concluded that evidence is insufficient to determine the balance of benefits and risks in women older than 75 years old, grading this recommendation as "l" (insufficient ${ }^{1}$ ), which ultimately means that the organization neither opposes or supports screening in this age group.

We agree that there is no robust data to clearly prove mortality reduction specifically for women over 75 years old. But what we know is that it has been shown that the benefit of mortality reduction from screening takes, on average, approximately five to seven years to become evident. ${ }^{17}$ As the sensitivity and positive predictive value of screening mammography increases with age,${ }^{18}$ one can expect better outcomes if cancers are found early. This is the rationale for ACR to recommend screening if life expectancy is higher than five to seven years. Finally, one must remember that in the USA, 80 years old women have nowadays, on average, a 10-year-life expectancy. ${ }^{19}$ In Portugal, women who are 65 years old have, on average, a 20-year-life expectancy. ${ }^{20}$

In conclusion, the skills of radiologist in imaging-based screening programs, and which provide unique expertise, should translate into an important position at the table of decisions if one wants to add true value to the healthcare screening policy. We think Portugal benefits from having an annual breast cancer screening program beginning at age 40 because, to our best scientific knowledge, more lives could be saved among women who choose to participate in breast cancer screening through the reduction of the incidence of fatal cancers.

\section{AUTHORS CONTRIBUTION}

CFS, EMA, JCM: Draft of the paper; critical review.

KLP: Critical review. Proficient review of the English language (native English speaker author).

\section{COMPETING INTERESTS}

No competing interests has been declared by any author.

\section{FUNDING}

No financial support was received by any author.

\section{REFERENCES}

1. Siu AL; U.S. Preventive Services Task Force. Screening for Breast Cancer: U.S. Preventive Services Task Force Recommendation Statement. Ann Intern Med. 2016;164:279-96.

2. Kopans DB. The Canadian National Breast Screening Studies are compromised and their results are unreliable: they should not factor into decisions about breast cancer screening. Breast Cancer Res Treat. 2017;165:9-15.

3. Bleyer A, Welch HG. Effect of three decades of screening mammography on breast-cancer incidence. N Engl J Med. 2012;367:1998-2005.

4. Monticciolo DL, Helvie MA, Hendrick RE. Current issues in the overdiagnosis and overtreatment of breast cancer. AJR Am J Roentgenol. 2018;210:285-91.

5. Puliti D, Duffy SW, Miccinesi G, de Koning H, Lynge E, Zappa M, et al. Overdiagnosis in mammographic screening for breast cancer in Europe: a literature review. J Med Screen. 2012;19:S42-56.

6. Zahl PH, Maehlen J, Welch HG. The natural history of invasive breast cancers detected by screening mammography. Arch Intern Med. 2008;168:2311-6.

7. Kopans DB. Point: The New England Journal of Medicine article suggesting overdiagnosis from mammography screening is scientifically incorrect and should be withdrawn. J Am Coll Radiol. 2013;10:317-9; discussion 323.

8. Merz B. Author of Canadian Breast Cancer Study retracts warnings. J Natl Cancer Inst. 1992;84:833-4.

9. Kopans DB. Arguments against mammography screening continue to be based on faulty science. Oncologist. 2014;19:107-12.

10. Welch HG, Prorok PC, O'Malley AJ, Kramer BS. Breast-cancer tumor size, overdiagnosis, and mammography screening effectiveness. N Engl J Med. 2016;375:1438-47.

11. Tabár L, Dean PB, Chen TH, Yen AM, Chen SL, Fann JC, et al. The incidence of fatal breast cancer measures the increased effectiveness of therapy in women participating in mammography screening. Cancer. 2019;125:515-23.

12. Mandelblatt JS, Cronin KA, Bailey S, Berry DA, de Koning HJ, Draisma $G$, et al. Effects of mammography screening under different screening schedules: model estimates of potential benefits and harms [published correction appears in Ann Intern Med. 2010;152:136]. Ann Intern Med. 2009;151:738-47.

13. Destounis $S$, Santacroce A. Age to begin and intervals for breast cancer screening: balancing benefits and harms. AJR Am J Roentgenol. 
2018:210:279-84.

14. Eby PR. Evidence to support screening women annually. Radiol Clin North Am. 2017;55:441-56

15. Lauby-Secretan B, Scoccianti C, Loomis D, Benbrahim-Tallaa L, Bouvard V, Bianchini F, et al. Breast-cancer screening--viewpoint of the IARC Working Group. N Engl J Med. 2015;372:2353-8.

16. Yaffe MJ, Mainprize JG. Risk of radiation-induced breast cancer from mammographic screening. Radiology. 2011;258:98-105.

17. Kerlikowske K, Salzmann P, Phillips KA, Cauley JA, Cummings SR. Continuing screening mammography in women aged 70 to 79 yearsimpact on life expectancy and cost-effectiveness. JAMA 1999;282:215663.
18. Lee $\mathrm{CH}$, Dershaw DD, Kopans D, Evans P, Monsees B, Monticciolo D, et al. Breast cancer screening with imaging: recommendations from the Society of Breast Imaging and the ACR on the use of mammography, breast MRI, breast ultrasound, and other technologies for the detection of clinically occult breast cancer. J Am Coll Radiol. 2010;7:18-27.

19. Centers for Disease Control and Prevention. National Vital Statistics Reports. [accessed 2021 Jul 3]. Available from: https://www.cdc.gov/ nchs/data/nvsr/nvsr67/nvsr67_07-508.pdf.

20. Pordata. Esperança de vida aos 65 anos: por sexo. [accessed $2021 \mathrm{Jul}$ 3]. https://www.pordata.pt/Europa/Esperan\%C3\%A7a+de+vida+aos+6 5+anos+por+sexo-1262. 